Proceedings of the Creative Construction Conference (2018)

Edited by: Miroslaw J. Skibniewski \& Miklos Hajdu

DOI 10.3311/CCC2018-012

Creative Construction Conference 2018, CCC 2018, 30 June - 3 July 2018, Ljubljana, Slovenia

\title{
Rethinking the roles in the AEC industry to accommodate digital fabrication
}

\author{
Borja García de Soto ${ }^{\mathrm{a}, \mathrm{b}, *}$, Isolda Agustí-Juan ${ }^{\mathrm{c}}$, Samuel Joss $^{\mathrm{d}}$, Jens Hunhevicz ${ }^{\mathrm{d}}$, Guillaume Habert ${ }^{\mathrm{c}}$, \\ Bryan Adey ${ }^{\mathrm{c}}$ \\ ${ }^{a}$ New York University Abu Dhabi (NYUAD), Saadiyat Island, Experimental Research Building, PO Box 129188, Abu Dhabi, UAE \\ ${ }^{b}$ New York University (NYU), Tandon School of Engineering, 6 MetroTech Center, Brooklyn, NY 11201, USA \\ ${ }^{c}$ Institute of Construction and Infrastructure Management, ETH Zurich, Stefano-Franscini-Platz 5, Zurich, 8093, Switzerland \\ ${ }^{d}$ ETH Zurich, Stefano-Franscini-Platz 5, Zurich, 8093, Switzerland
}

\begin{abstract}
As robots and other technologies take over tasks previously performed by construction workers and planners, the concern about the future of jobs and wages will increase. While digital fabrication (dfab), and particularly the use of robotic technology, has the potential to improve productivity, it should not necessarily reduce total employment in the construction sector in the long run. It is expected that existing roles will evolve, mainly related to the human-robot interaction, and new roles will be created (e.g., in addition to designers there would be a need for employees with digital skills). Particular attention should be made to the transition phase in which conflicts may occur between the old and new systems and planning methods. This will occur for different functions and services during the planning and execution of construction projects. Focusing on the construction phase of a concrete wall using additive dfab for the NEST building located in Dübendorf, Switzerland, the different roles were evaluated. From this study, it seems that robotic technologies and conventional construction will coexist next to each other for a while, leading to a higher job variability and the creation of new roles, such as dfab managers to support coordination required, dfab programmers to develop computer numerical control that can be implemented with industrial robots, or dfab technicians to support robotic systems. However, there is still a lot of uncertainty, making it difficult to quantify employment impacts. Therefore, further research is needed to evaluate the impacts of using dfab to the functional division, supply chain and business models of the AEC industry, and to assess additional social impacts, such as changes in education schemes.
\end{abstract}

(C) 2018 The Authors. Published by Diamond Congress Ltd., Budapest University of Technology and Economics Peer-review under responsibility of the scientific committee of the Creative Construction Conference 2018.

Keywords: construction automation; digital fabrication (dfab); human-robot interaction; industrialized construction; integrated project delivery (IPD); project delivery and contract strategies, robotic construction; roles in the AEC industry

\section{Introduction}

Construction is distinguished from manufacturing in that the bulk of the production tasks typically occurs in a field setting and is undertaken in an uncontrolled environment [1]. Moreover, buildings are complex systems that cannot be conceived as serial products, such as an automobile for example [2]. Each building is designed and constructed according to specific conditions and stakeholder decisions, making automation harder to implement when compared to other industries (e.g., manufacturing). Automation involves machines, tools, devices, installations, and systems that are all platforms developed by humans to perform a given set of activities without human involvement. Although there are many definitions for automation, mostly depending on the sector in which it is used, there is no doubt that it is powerful. As Nof [3] said, automation "has a tremendous impact on civilization, on humanity, and it may carry risks." For this study, the concept of automation is directly related to the use of robotic systems or robots to assist construction workers or to perform construction tasks during onsite operations. In particular, this study deals with onsite robotic fabrication applied to additive construction, referred in this study as digital fabrication (dfab). 
Despite the fact that the construction industry is one of the oldest and represents a significant part of a country's GDP, it is also one of the most unfamiliar regarding the R\&D fields for the automation community [4]. However, the research of robotic fabrication and robotic systems applied to construction operations is not new and has been around since the 80s. In 1984 Warszawski [5] published one of the first critiques about the use of robots in the building sector, trying to examine robot requirements, implementation and economic feasibility of their application. Exploratory studies were conducted in the fields of infrastructure ([6], [7], [8], [9]), digital design and production [10], surveying [11], prefabrication ([12], [13]) and assembly [14]. In addition, researchers started investigating the feasibility of robotic applications in various architecture and construction activities ([15], [16], [17]) and also for freeform construction ([18], [19]). Combination of construction automation with robotics has also been investigated ([20], [4]). However, early attempts in robotic construction did not succeed mostly because of the lack of computation power, and partly because of the highly specialized character of the robot developed and used [21].

Although the use of robotic systems, mainly those used onsite, is still very limited (a few examples include the Semi-Automated Mason [22] and the In situ Fabricator [23]), they are becoming technically and economically possible, and it is expected that they will gradually be used in the industry as cost-effective solutions are found. Another driving force pushing contractors to give a more serious look at robotics and automation is the shortage of construction workers. The aging working population coupled with the lack of new generation joining the construction workforce are giving construction companies a hard time finding qualified labor [24]. According to a survey by Autodesk and the Associated General Contractors of America (AGC), 70\% percent of construction firms are having difficulties finding qualified craft workers to hire during growing construction demand [25]. This interest is not new. Something similar happened in the 1980s in Japan, where construction demand was booming. However, construction jobs were not attractive to young Japanese generations which triggered a substantial investment and research into construction robotics. After a significant amount of resources invested in the development of highly customized automation systems and robots, the technical excellence was never matched by economic success, causing the abandonment of the robotic pursuit in construction [26].

The study presented in this paper provides an outlook of the findings during the evaluation of an ongoing project in Switzerland in which robots are used for digital fabrication on site. Particular attention was given to the changing roles during the construction execution phase. Given the research and prototype nature of the case study, the observations from this study should only be considered as exploratory and not as a generalization for the construction industry. However, this type of studies can be useful to evaluate trends and changes in the roles of other projects and eventually forge new directions in the construction sector.

\section{Current situation}

\subsection{Uncertain impacts on labor and workforce}

As robots and other technologies take over tasks previously performed by construction workers, there will be a disruption in the current roles, from laborers to designers. This transformation in the construction sector will be accompanied by the concern about the future of jobs and an increase in wages. According to [27] $41 \%$ of construction jobs in Germany are at high risk of automation by $2030.35 \%$ in the US, $26 \%$ in Japan and $24 \%$ in the UK. Studies for other industries have also investigated the effect of robots and automation to the social dimension. Frey and Osborne [28] estimated that around 47\% of total US employment has a "high risk of computerization" by the 2030s, while the estimations by Arntz et al. [29] were quite a bit lower, only 10\%. The findings in [27] are somewhere in between, estimating that $35 \%$ of US jobs are in danger of being lost to the robots. Recent debates about the future of jobs have mainly focused on whether or not they are at risk of automation ([27], [28], [29], [30]). Most studies have minimized the potential effects of automation on job creation, and have tended to ignore other relevant trends, including globalization, population aging, urbanization, and the rise of the green economy [31].

Although some studies and projections are pessimistic about the impacts to labor [28], others give a more optimistic view ([29], [32]), which is shared by the authors. The creation of new and specialized roles always happens when new technologies are introduced, and it is expected that the same will occur in the construction sector. While dfab will increase productivity ([33], [34]) it should not necessarily reduce total employment in the long run. On the contrary, robots and automation will create new jobs and provide new opportunities. It is expected that existing roles will evolve, especially during the transition phase (i.e., human-robot interaction), and new roles will be created. As indicated by [35], instead of drafters there would be a need for workers with more digital skills. This will occur for different functions and services, including planning and execution. The exact impact of the need of new roles, such as dfab Technicians to support robotic systems, dfab Programmers to develop computer numerical control that can be implemented with industrial robots, or dfab Managers and Coordinators, needs to be investigated in future research. One of the main advantages of using robotics in construction has to do with the potential to assist construction workers during the performance of repetitive or dangerous construction tasks in an autonomous manner, or with little supervision from laborers. This has the potential to make workers safer and reduce hazards, while also increasing 
productivity and benefitting the whole construction industry [36]. In addition, quality is expected to improve as robots would be able to deal with quality issues during production [37].

When comparing to traditional construction project phases, digital fabrication brings a significant change, particularly during the planning and construction phases. Digital fabrication introduces sophisticated human-robot collaboration based on robot sensory inputs. This builds a common base for exchange and collaboration among participants of different skillsets and machines. Many publications are about robots taking our jobs [38], or how machine learning, artificial intelligence, and automation, with the potential of outperforming humans, will eventually cause manual jobs to disappear ([39], [40]). The reality is far from those views, and current robotic systems and artificial intelligence are limited in their abilities to replace humans due to their inability to understand the complexity of our most basic real environment ([41]). Despite the unquestionable advancements in those areas, robots will not replace humans but will help them to make some tasks more efficient.

\subsection{Traditional roles and responsibilities}

The number of stakeholders in construction projects varies significantly, but in general, their number is considerable, and their interactions are complex [42]. The most basic parties can be grouped into the owner (or project sponsor), the designer/engineer, the contractor, financial/legal/marketing institutions, and the general public/user. These main parties have different important roles involved. For purposes of this study, we will focus on the designer/engineer and the contractor during the design and execution phases as indicated in Table 1. The different terminology used and key responsibilities are according to the service model from the Swiss Society of Engineers and Architects [43]. Slight variations regarding their name and responsibilities might be observed in different countries.

Table 1. Main roles and their key responsibilities

\begin{tabular}{|c|c|c|}
\hline & Role & Main task \\
\hline \multirow{3}{*}{ 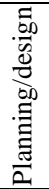 } & Leading designer/planner (project manager) & To coordinate the design/planning team \\
\hline & Designer/engineer & $\begin{array}{l}\text { To design a particular part of the project and often does the specialist site management } \\
\text { for the part planned/designed }\end{array}$ \\
\hline & CAD drafters & To prepare detailed technical plans or drawings \\
\hline \multirow{3}{*}{ 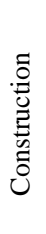 } & Construction manager & $\begin{array}{l}\text { To coordinate the planning and execution of work on-site as a representative of the } \\
\text { owner }\end{array}$ \\
\hline & Site supervisor & $\begin{array}{l}\text { To manage contractor's team by assisting with the monitoring of onsite operations. } \\
\text { Typically under the supervision of the construction manager }\end{array}$ \\
\hline & Worker & $\begin{array}{l}\text { To do the manual execution of the planned work, in most cases with the support of } \\
\text { machines and tools }\end{array}$ \\
\hline
\end{tabular}

\section{Case study}

The investigation of the different processes and interaction among the project participants was done from February to July 2017 by graduate students doing their Master Theses at the department of Civil Engineering in ETH Zurich. They used the planning and execution of some elements from the NEST (Next Evolution in Sustainable Building Technologies) building, a research and innovation building being built at the Swiss Federal Laboratories for Materials Science and Technology (Empa by its German acronym) in Dübendorf, Switzerland. The observations made are only an excerpt of the ongoing processes of the NEST building. The NEST building is the backbone of several units aimed to test and advance technologies, materials, and systems under real conditions. One of those units is the DFAB HOUSE, a project lead by Empa in collaboration with the NCCR Digital Fabrication, ETH Zurich, and industrial partners. The unit consists of a three-story building (Figure 1).

Having several floors was done on purpose to show that dfab is possible for multi-story buildings. The DFAB HOUSE consists of four sub-projects, each carried out by a research team. The sub-projects are the Mesh Mould Wall, the Smart Slab, the Smart Dynamic Casting, and the Spatial Timber Assemblies. The different projects are summarized in Table 2. 


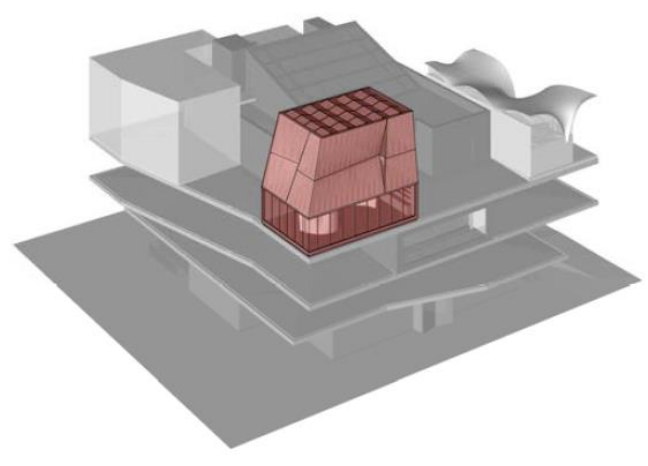

(a)

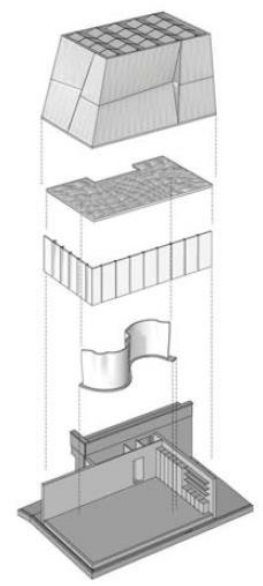

(b)

Fig. 1. (a) Empa's NEST building; (b) Different components of the DFAB HOUSE (source: NCCR Digital Fabrication, 2017).

The organization of the DFAB HOUSE project is rather complex since the two big entities EMPA and NCCR, as well as all other consultants and contractors, have to be integrated. The complicated organizational form is a direct consequence of the different research projects, involving many parties and decision makers. However, given the research nature of the project, there is a collaborative interaction among all the stakeholders not common in most public construction projects. The project delivery approach used was a combination between the Design-Build and Integrated Project Delivery System (IPD) [44], which allowed a superposition between the planning and execution phases as well as a fusion between the planner, designer, and contractor through collaborative interaction, particularly during the early phases of the project.

Table 2. Different projects for the DFAB HOUSE and general description

\begin{tabular}{ll}
\hline Project & General description \\
\hline $\begin{array}{l}\text { Mesh Mould Wall } \\
\text { Smart Slab Team }\end{array}$ & $\begin{array}{l}\text { To produce freeform loadbearing walls that can contain building services, with a steel mesh, assembled robotically } \\
\text { on site with the In situ Fabricator }\end{array}$ \\
$\begin{array}{l}\text { To investigate the potential of additive manufacturing (3D printing) for the prefabrication of large-scale lightweight } \\
\text { integrative building components }\end{array}$ \\
$\begin{array}{l}\text { Casting Team } \\
\text { Spatial Timber }\end{array}$ & To automatically produce structures with variable geometry using the slip-forming technology \\
Assemblies & To prefabricate a timber module robotically and assemble the elements on site \\
\hline
\end{tabular}

The project schedule was done using lean principles, in particular, the use of the Last Planner System. In addition, frequent meetings were also conducted among the different teams to ensure proper coordination. Although those meetings did not strictly follow the scrum concept [45], mostly because many of the artifacts were not considered, they followed a similar structure. As a coordination tool for the architect, the project manager, the designers and the research teams, several systems (e.g., Favro, Trimble) were used. The shared online platform was accepted and used by all participants since it was intuitive and familiar for most team members.

\subsection{Evolution of existing roles and creation of new ones}

The evaluation of the traditional roles observed during the planning and execution during the five months of interaction with the different participants at the DFAB HOUSE is summarized below. Only the roles related to the case study are addressed. There might be a number of additional roles which would be affected or would be created but are not considered in this study; therefore, the roles identified here should be used for illustration purposes only and not meant for generalization to the construction industry adopting automation and new technologies. 


\subsubsection{Planning phase}

During the planning phase, most of the traditional roles are still applicable, but with some modifications regarding their primary tasks. For example, the project manager maintains most tasks as they are now, but as the projects become more automated or influenced by new technology, the coordination among the different project participants will be shifted towards new roles (e.g., dfab Manager). The role of engineers and designers during this phase will also remain very similar. Main changes were related to the implementation of the new working platform (e.g., using BIM) and using new software applications, such as the specialized plug-ins developed for the DFAB HOUSE. Similarly, CAD drafters would not change too much, only they will need to adapt to the new parametric software used to represent the different elements specified by the engineers/designers, their involvement would also be reduced as the automation of the project increases, but their need will not disappear completely. Also, new roles would be required. For example, dfab Managers, dfab Coordinators, or dfab Programmers.

The dfab Manager is a new role. This role arises once dfab becomes more preponderant in a project (similar to BIM managers in BIM-based projects). Some of the key tasks of the dfab Manager include:

- Writing and enforcing the dfab report (a report defining the scope of dfab) in cooperation with the project manager, the owner, and the involved designers.

- Defining the dfab goals.

- Defining the tasks, competencies, and liabilities concerning dfab for the different project participants.

- Defining the standards for the BIM models, model use, model exchange during planning, execution, and operation (at least the model handover to the owner).

- Defining the standards of dfab on the construction site. This includes soft- and hardware standards and interface and communication protocols used.

The dfab Manager is a highly experienced the field of dfab and knows the constraints of automated construction systems in general, and what are the elements to implement during the planning phase in order to have an efficient execution. She or he advises the owner regarding which level of automation might be optimal for the project. Since the whole set up of the project is done at the beginning of the project, the dfab Manager is also required then, or at the latest when the planner is hired. Once the set-up is done, the dfab Manager service for the project is done, and she or he might only be called for further strategic question arising during the planning process. The BIM manager could be brought into the project either as a client advisor or (specialist) consultant.

The role of the dfab Coordinator arises as soon as there is model coordination in a standardized way. Her or his level of expertise in the field of dfab is not as much as that of the dfab Manager. Since the planning of automated construction is suggested to be added to the BIM software, the main tasks of the dfab Coordinator include:

- Determining the coordination and methods required.

- Checking and validating of partial models (clash-detection), including the automated construction planning on site.

- Determining the necessary corrections, together with the project manager and the involved planners.

The dfab Coordinator is required in the project as soon as the BIM platform is set up. Her or his mandate would normally be included in the mandate for the project manager, meaning the planning office must have the necessary dfab knowledge and people. This is usually during the preliminary project or the construction project. Her or his role only ends once the models are delivered to the client during the close-out.

The role of the designer's dfab Programmer is related to software design, which could be adapted from project to project. The main tasks would include coordination of the software (including fixing compatibility issues between participants and installation of plug-ins) and organization of the data storage and backup. The dfab Programmer is in charge of everything related to software, preparing it, so that the planners can work at their level of understanding of informatics. The dfab Programmer is mainly required in the planning process, as soon as the BIM platform is set-up, which is done in the preliminary project. It could be thinkable that the organization that is managing the project also brings in the programmer since their work is related. She or he stays available for the construction manager during the execution.

The utilization of these roles, or their participation share, changes depending on the amount of automation or technology (i.e., the level of digitalization) used in a project. A qualitative representation of this participation based on the level of digitalization is shown in Figure 2. Only the roles being discussed are considered (other roles might be applicable) and the variation shown is a qualitative assessment from the author's observation of the case study. As depicted in Figure 2, the dfab Manager and the dfab Programmer only appear at an increased level of digitalization, since at low levels the tasks lay within the competences and knowledge of the current roles. 


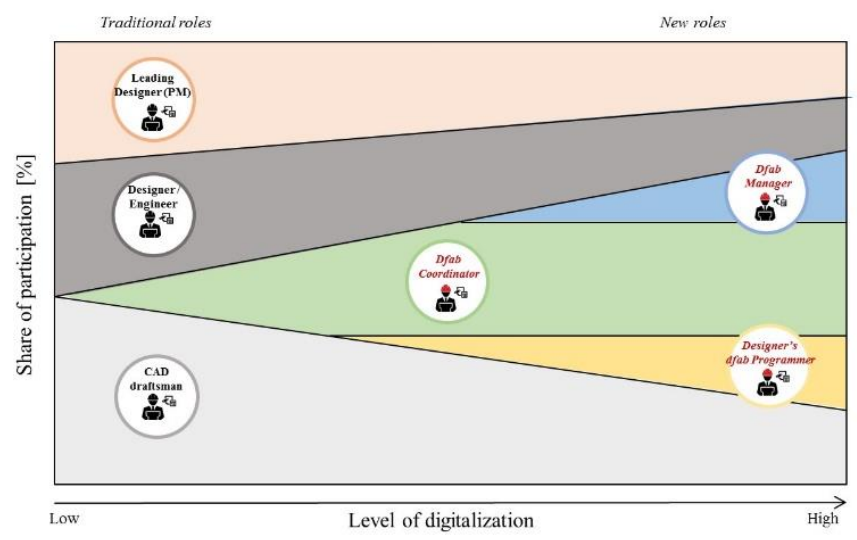

Fig. 2. Qualitative share of participation of each role vs. degree of digitalization during in the planning phase.

\subsubsection{Execution phase}

During the execution phase, most of the traditional roles are still applicable, but with some modifications regarding their main tasks or level of involvement. For example, the construction manager maintains most tasks as they are now; however, there is a shift of their workload due to the availability and reliability of information (e.g., fewer efforts to monitor and control schedule and cost, but more efforts to coordinate with programmers). Similar to the construction manager, the site supervisor's scope does not change a lot, but the workload shifts towards detail planning and monitoring of the robotic systems from a control room. With regards to the construction worker, her or his presence would be affected based on the amount of automation and digitalization used. One can think of this as an evolution from construction worker to dfab Technician. This would be an individual with experience in the execution of specific tasks, and that has been trained to operate or provide support to one or a few automated systems, similar to operators of heavy machinery (e.g., cranes, excavators) in current projects. Some of their tasks would include setting up the machine on site, supply the system with raw material. In essence, the dfab Technician does all standard tasks that are required to ensure a smooth development of the automated construction processes.

Another new role is the contractor's dfab Programmer. The scope defined for the designers' dfab Programmer during the planning phase is also applicable to her or him, but only internally to the contractor. However, for the internal task, there is a main difference: while the tasks of the designer's programmer are about creating the framework for planning, the tasks for the contractor's programmer consist of deducing the necessary codes for the robots from the BIM model. This also consists of the temporal planning (4D, in active interaction with the site supervisor and coherently to the timeline defined by the planners). The whole planning can then be checked by the dfab Coordinator, including the planning of all different contractors, showing the problematic points easily. The dfab Programmer is involved in the process as soon as the contractor is involved. Her or his work is then ongoing for detail-programming and adaption until the building is erected.

Similar to the planning phase, the participation share of the different roles would change depending on the level of digitalization of a project. A qualitative representation of their participation, based on the level of digitalization, is shown in Figure 3. Only the roles being discussed are considered (other roles might be applicable) and the variation shown is a qualitative assessment from the author's observation of the case study.

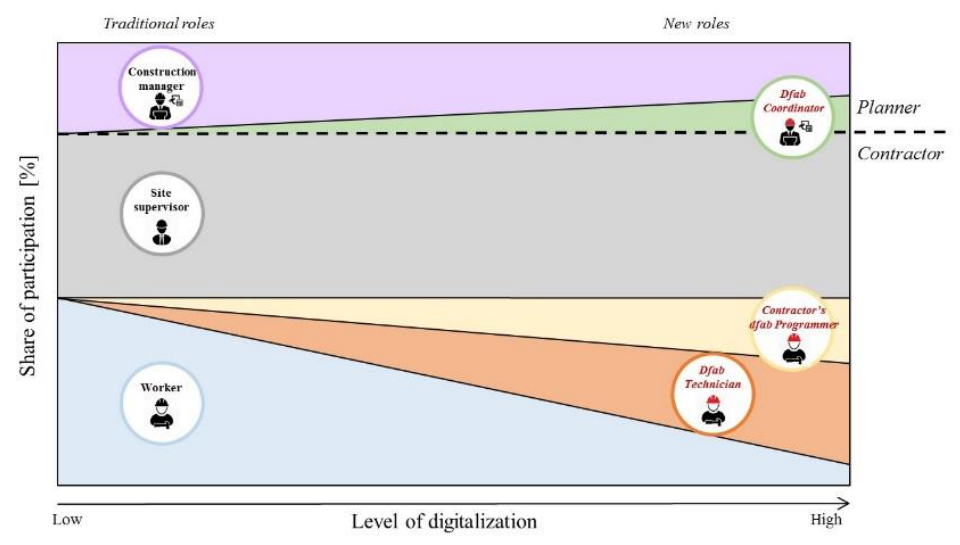

Fig. 3. Qualitative share of participation of each role vs. degree of digitalization during in the execution phase. 


\section{Conclusion and outlook}

The creation of new and specialized roles always happens when new technologies are introduced, and it is expected that the same will occur in the construction sector. When comparing to traditional construction project phases, digital fabrication brings a significant change, particularly in the planning and execution phases. As a result, it is expected that current construction roles evolve, and new roles are created. There will always be tasks that will not be fully automated. The construction workers will not disappear, but their number will be reduced as the level of digitalization of a project increases. What is expected to occur is that the responsibilities of the construction workers will shift from unsafe and hard conditions to safer and less labor intensive, such as to monitor and control automated processes by transferring their know-how to the robotic systems. Although this study is not meant to be an exact representation of how the AEC roles will change, it opens the debate and research in this area, so that future studies can use this work as a guideline.

Further research is needed to evaluate the impacts of using dfab to the functional division, supply chain, and business models, as wells as the project delivery and contract strategies of the AEC industry, and to assess additional social impacts, such as changes in education and training schemes.

\section{Acknowledgments}

This research was supported by the National Centre of Competence in Research, NCCR Digital Fabrication, which was funded by the Swiss National Science Foundation (project number 51NF40_141853). We would like to thank the different research teams from the DFAB HOUSE at the NEST building; special thanks are given to Konrad Graser and Pascal Breitenstein for their support during the work conducted in this study.

\section{References}

[1] Saidi K.S., O’Brien J.B., Lytle A.M. (2008). Robotics in Construction. In: Siciliano B., Khatib O. (eds) Springer Handbook of Robotics. Springer, Berlin, Heidelberg. https://doi.org/10.1007/978-3-540-30301-5_48

[2] Gramazio, F., Kohler, M. \& Willmann, J. (2014). The Robotic Touch: How Robots Change Architecture, Park Books.

[3] Nof S.Y. (2009). Automation: What It Means to Us Around the World. In: Nof S. (eds) Springer Handbook of Automation. Springer, Berlin, Heidelberg. https://doi.org/10.1007/978-3-540-78831-7_3

[4] Balaguer, C., Abderrahim, M., (2008). Robotics and Automation in Construction, University Carlos III of Madrid, Madrid, Spain. ISBN: 978-953-7619-13-8

[5] Warszawski, A. (1984). Robotics in Building Construction, Technical Report R-84-147, Department of Civil Engineering, Carnegie-Mellon University, Pittsburgh, PA

[6] Herbsman, Z., and Ellis, R. (1988). Potential application of robotics in highway construction, Proceedings of the 5th International Symposium on Robotics in Construction, Japan Industrial Robot Association, Tokyo, Japan, June, 299-308

[7] Kobayashi, T., Honda, S., \& Tsukhara, Y. (1988). Study on a robotic system for pavement cutting work. In Proc, 5th Int. Symp. on Robotics in Constr., Japan Industrial Robot Association, Tokyo, Japan, June (pp. 289-298).

[8] Skibniewski, M., Hendrickson, H. (1990). Automation and robotics for road construction and maintenance, Journal of Transportation Engineering, 114(3), 261-271

[9] Caldas, C., and Goodrum, P. (2010). Construction Robotics: The Dream vs. Reality, White Paper \#125, Construction Industry Institute (CII), Austin, TX, Retrieved June 25, 2015, from https://www.construction-institute.org/scriptcontent/btsc-pubs/CII-BTSC-125.doc

[10] Bock, T., (2008). Digital design and robotic production 3-D shaped precast components, E.K. Zavadskas, A. Kaklauskas, M.J. Skibniewski (Eds.), The 25th International Symposium on Automation in Construction, Technika, Vilnius, 2008, 11-21, ISARC-2008, Selected papers

[11] Vähä, P., Heikkilä, T., Kilpeläinen, P., Järviluoma, M., \& Gambao, E. (2013). Extending automation of building construction—Survey on potential sensor technologies and robotic applications. Automation in Construction, 36, 168-178.

[12] Benjaoran, V., Dawood, N. (2006). Intelligent approach to production planning system for bespoke precast concrete products, Automation in Construction, 15, $737-745$

[13] Hu, W (2005). Automatic Construction Process of Prefabricated Buildings on Geometric Reasoning, Proceedings of Construction Research Congress (CRC) 2005, San Diego, CA, USA

[14] Chu, B., Jung, K., Lim, M., and Hong, D. (2013). Robot-Based Construction Automation: An Application to Steel Beam Assembly (Part I), Automation in Construction, 32, 46-61

[15] Boles, W., Maxwell, W. (1995). Construction Automation and Robotics, Pathway to Implementation, Journal of Construction Engineering and Management, 121(1), 143-152

[16] Everett, J. G., \& Slocum, A. H. (1994). Automation and robotics opportunities: construction versus manufacturing. Journal of construction engineering and management, 120(2), 443-452

[17] Warszawski, A. and Rosenfeld, Y. (1994). Robot for Interior Finishing of Works in Building Feasibility Analysis, Journal of Construction Engineering and Management, 124 (1), 31-41

[18] Lim, S., Buswell, R.A., Le, T.T., Austin, S.A., Gibb, A.G.F. \& Thorpe, T. (2012). Developments in construction-scale additive manufacturing processes. Automation in Construction, 21, 262-268.

[19] Buswell, R.A., Soar, R.C., Gibb, A.G.F. \& Thorpe, A. (2007). Freeform Construction: Mega-scale Rapid Manufacturing for construction, Automation in Construction, 16, 224-231

[20] Morales, G., Herbzman, Z., Najafi, F., T. (1999). Robots and construction automation, Proceedings of ISARC 1999, 16th Automation and Robotics in Construction, Madrid, Spain, 283-288

[21] Balaguer, C., Gambao, E. and Gebhardt, F., (1999). A Robotic System for Automated Masonry, Journal of Automation in Construction, 599602

[22] SAM100 (n.d.) Semi-Automated Mason by Construction Robotics. Available at http://www.construction-robotics.com/sam100/ (accessed on October 15, 2017) 
[23] Giftthaler, M., Sandy, T., Dörfler, K., Brooks, I., Buckingham, M., Rey, G., . . Buchli, J. (2017). Mobile robotic fabrication at 1: 1 scale: The in situ fabricator. Construction Robotics, $1-12$

[24] Harris, C. (2018). Construction worker shortage a global issue: UK expert. Available at: https://www.stuff.co.nz/business/property/102064018/construction-worker-shortage-a-global-issue-uk-expert (accessed on March 12, 2018)

[25] AGC (2017). Seventy-Percent of Contractors Have a Hard Time Finding Qualified Craft Workers to Hire Amid Growing Construction Demand, National Survey Finds. The Associated General Contractors of America. Available at https://www.agc.org/news/2017/08/29/seventy-percent-contractors-have-hard-time-finding-qualified-craft-workers-hire-am-0 (accessed on March 10, 2018)

[26] Bechthold, M. (2010). The return of the future: a second go at robotic construction. Architectural Design, 80(4), 116-121

[27] Berriman, R. (2017) Will robots steal our jobs? The potential impact of automation on the UK and other major economies. PwC. Part of the UK Economic Outlook March, 2017. Available at: http://www.pwc.co.uk/economic-services/ukeo/pwc-uk-economic-outlook-full-reportmarch-2017-v2.pdf (accessed on April 2017)

[28] Frey, C. B., Osborne, M. A. (2017). The future of employment: how susceptible are jobs to computerisation? Technological Forecasting and Social Change 114, 254-280

[29] Arntz, M., Gregory, T., and Zierahn, U. (2016), The Risk of Automation for Jobs in OECD Countries: A Comparative Analysis, OECD Social, Employment and Migration Working Papers, No. 189, OECD Publishing, Paris. http://dx.doi.org/10.1787/5jlz9h56dvq7-en

[30] Acemoglu, D., \& Restrepo, P. (2017). Robots and Jobs: Evidence from US Labor Markets. NBER Working Paper No. 23285. Available at http://www.nber.org/papers/w23285 (accessed on September 2017)

[31] Bakhshi, H., Downing, J., Osborne, M. and Schneider, P. (2017). The Future of Skills: Employment in 2030. London: Pearson and Nesta. ISBN: 978-0-992-42595-1

[32] OECD (2016). Automation and Independent Work in a Digital Economy, Policy Brief on The Future of Work. OECD Publishing, Paris.

[33] Castro-Lacouture, D. (2009). Construction automation. In Springer handbook of automation (pp. 1063-1078). Springer, Berlin, Heidelberg. https://doi.org/10.1007/978-3-540-78831-7_61

[34] García de Soto, B., Agustí-Juan, I., Hunhevicz, J., Joss, S., Graser, K., Habert, G., and Adey, B. (2018). Productivity of digital fabrication in construction: cost and time analysis of a robotically built wall. Automation in Construction, 92, 297-311. https://doi.org/10.1016/j.autcon.2018.04.004

[35] Gerbert, P., Castagnino, S., Rothballer, C., Renz, A., Filitz, R. (2016). Digital in Engineering and Construction. The Transformative Power of Building Information Modeling. The Boston Consulting Group. Available at http://futureofconstruction.org/content/uploads/2016/09/BCGDigital-in-Engineering-and-Construction-Mar-2016.pdf (accessed on May 13, 2017)

[36] Bernold, L. E. (1987). Automation and robotics in construction: a challenge and a chance for an industry in transition. International Journal of Project Management, 5(3), 155-160

[37] Tilley, J. (2017). Automation, robotics, and the factory of the future. McKinsey \& Company. Available at: https://www.mckinsey.com/business-functions/operations/our-insights/automation-robotics-and-the-factory-of-the-future (accessed on January 2, 2018)

[38] Fagan, D. (2017). Will technology take your job? New analysis says more of us are safer than we thought, but not all. Available at: https://theconversation.com/will-technology-take-your-job-new-analysis-says-more-of-us-are-safer-than-we-thought-but-not-all-86219 (accessed on 11/01/2017)

[39] Welsh, S. (2016). Are we ready for Robotopia, when robots replace the human workforce? Available at: https://theconversation.com/are-weready-for-robotopia-when-robots-replace-the-human-workforce-63653 (accessed on October 15, 2017)

[40] Waters, R. (2017). The impact of cobots on workers'wellbeing. Available at: https://www.ft.com/content/a0b8e562-3734-11e7-99bd13beb0903fa3 (accessed on 09/22/2017)

[41] Moniz, A. B., \& Krings, B. J. (2016). Robots working with humans or humans working with robots? Searching for social dimensions in new human-robot interaction in industry. Societies, 6(3), 23.

[42] Cleland, D. I. 1986. Project Stakeholder Management. Project Management Journal 17(4):36-44.

[43] SIA 112 (2001): Service Model. Swiss Society of Engineers and Architects, Zurich

[44] AIA, (2017). Integrated Project Delivery: A Guide. The American Institute of Architects, AIA, Version 1, 2007. Available at https://info.aia.org/SiteObjects/files/IPD_Guide_2007.pdf (accessed on April 24, 2017)

[45] Streule, T., Miserini, N., Bartlomé, O., Klippel, M., \& Garcia de Soto, B. (2016). Implementation of scrum in the construction industry. Procedia engineering, 164, 269-276. https://doi.org/10.1016/j.proeng.2016.11.619 